\title{
Correlating Hemodynamic Changes and Occlusion Time after Flow Diverter Treatment of Bilateral Large Internal Carotid Artery Aneurysms
}
A. C.-O. Tsang 1,3,*

Phone +85222553368

Email acotsang@hku.hk
A. Y.-S. Tang 2
W. C. Chung 2
G. K.-K. Leung 1
K. W. Chow 2

1 Department of Surgery, Li Ka Shing Faculty of Medicine, The University of Hong Kong, Pokfulam, Hong Kong

2 Department of Mechanical Engineering, The University of Hong Kong, Pokfulam, Hong Kong

3 Department of Neurosurgery, Queen Mary Hospital, 102 Pokfulam Road, Pokfulam, Hong Kong

\section{Background}

Flow diverters such as the Pipeline Embolization Device (Covidien Vascular Therapies, Mansfield, MA, USA) (PED) are gaining popularity in the treatment of unruptured cerebral aneurysms. Their clinical efficacy is well established with complete occlusion rate in the range of 76-83\% [1, $2]$. However, the underlying hemodynamic factors that determine treatment outcome are not well understood.

Computational fluid dynamics (CFD) is a technique increasingly employed in the study of the hemodynamic effect of flow diverters in intracranial 
aneurysms, aiming to identify flow parameters predictive of clinical outcome [3-6]. We identified a unique patient harboring bilateral internal carotid artery (ICA) aneurysms located in comparable positions who was treated with PED alone. The left aneurysm occluded in the typical time frame of 1 year, whereas the right aneurysm persisted for 3 years before occlusion. As both aneurysms are affected by the same hematological and vasculo-endothelial factors of the same patient, the difference in clinical outcome is primarily due to the different hemodynamic effect imposed by PED. We investigated the hemodynamic effect of flow diverter in these two aneurysms using CFD and report the parameters that may correspond to aneurysm occlusion.

\section{Case presentation}

A middle-aged lady in good health presented right abducens nerve palsy. Magnetic resonance imaging (MRI) of the brain showed bilateral cavernous ICA aneurysms. The left aneurysm measured $9 \times 7 \mathrm{~mm}$ whereas the right aneurysm measured $22 \times 15 \mathrm{~mm}$, with mass effect on the cavernous sinus, explaining her symptoms (Fig. 1). Both were wide-neck aneurysms and were treated with PED alone sequentially, 3 months apart. She was loaded with Aspirin $300 \mathrm{mg}$ and Clopidogrel $300 \mathrm{mg}$ before treatment, with Aspirin continuing for 6 months and Clopidogrel for 3 months afterwards. There were no procedural complications.

\section{Fig. 1}

MR angiogram image showing the configuration of left (long arrow) and right aneurysm (short arrow) 


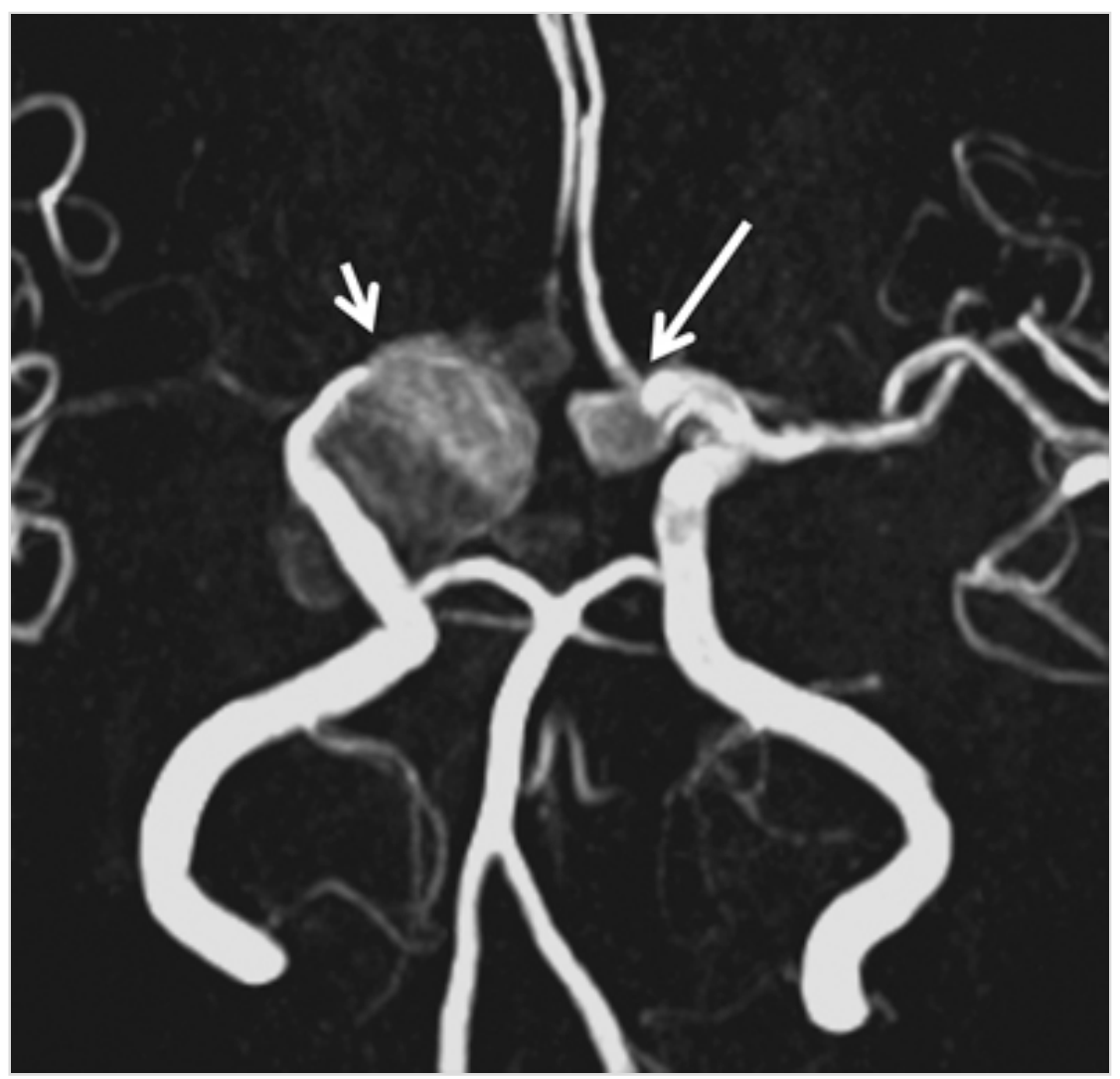

Digital subtraction angiogram at 1 year showed that the left aneurysm was completely occluded, whereas the right aneurysm had partially thrombosed but with a persistent filling. The right aneurysm persisted on CT angiogram at 2 years but with significant shrinkage and finally occluded at a 3-year follow-up (Fig. 2). The patient's diplopia gradually improved after 3 years.

\section{Fig. 2}

a, b Axial contrast CT angiogram image at 3 years after operation showing both aneurysms were occluded with marked shrinkage in size, whereas the stented internal carotid arteries remain patent. c Reconstructed CT angiogram image showing resolution of both carotid aneurysms 

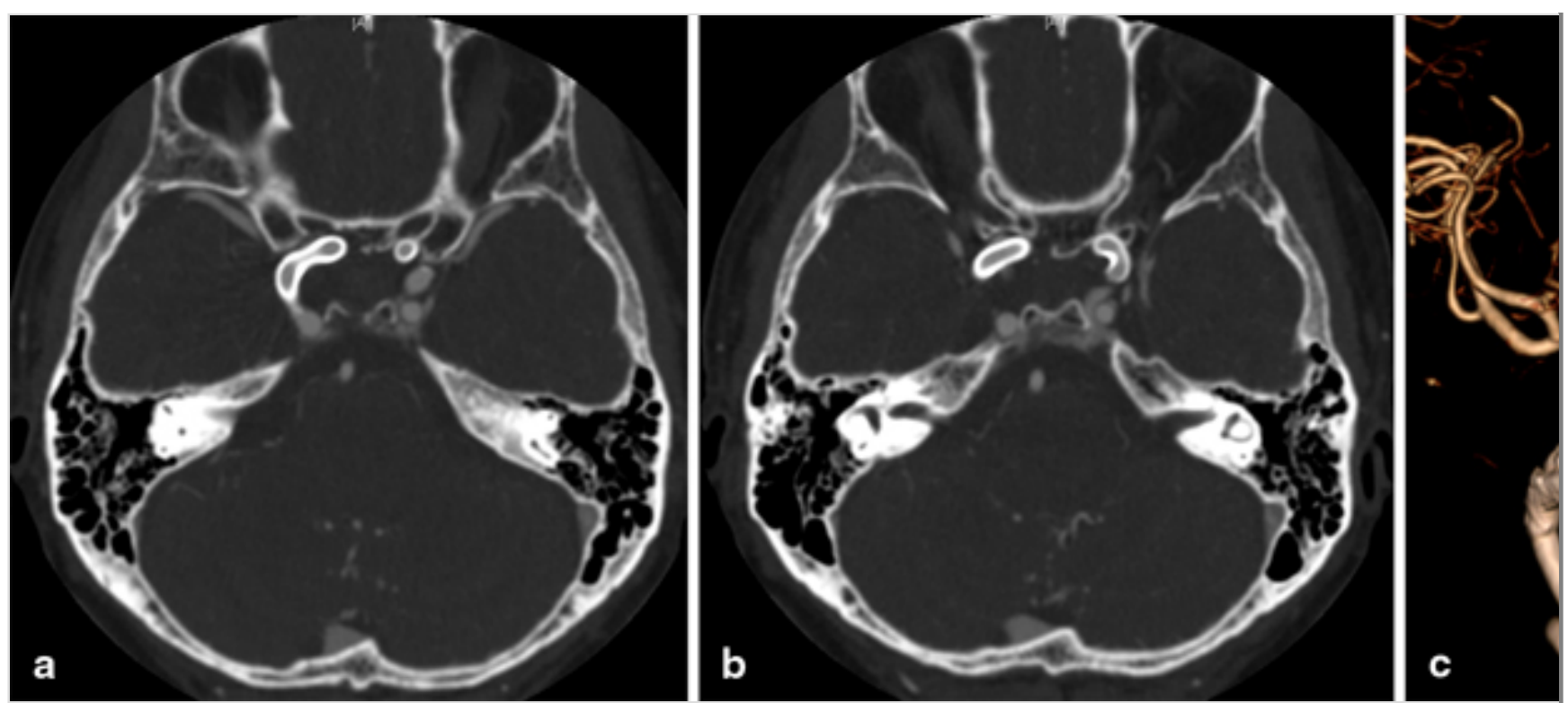

\section{Methods}

Our technique of patient-specific aneurysm modeling and virtual deployment of the PED was previously verified experimentally with in vitro aneurysm models through ultrasound imaging [7]. Three-dimensional geometrical models of both aneurysms were constructed based on MR angiograms with Mimics (Materialise, Leuven, Belgium). A virtual flow diverter accurately configured to the real PED was deployed to cover the aneurysm neck with SOLIDWORKS (Dassault Systemes, USA).

A pulsatile flow profile with peak flow rate of $7.6 \mathrm{ml} / \mathrm{s}$ was imposed at the ICA inlet, whereas an unsteady pressure waveform with $120 / 80 \mathrm{mmHg}$ was prescribed at the outlets [8]. Blood was modeled as Newtonian fluid with a density of $1060 \mathrm{~kg} / \mathrm{m}^{3}$ and a viscosity of $0.0035 \mathrm{~kg} /(\mathrm{ms})$. The vessel wall and the stent were modeled as rigid with no-slip conditions. The threedimensional fluid motion was governed by the principles of mass and momentum conservation; these evolution equations were iteratively solved by the unsteady solver in FLUENT (ANSYS, Canonsburg, Pennsylvania, USA).

\section{Results}

The left aneurysm completely occluded at 1 year after PED, whereas the right aneurysm persisted for 3 years before eventual occlusion. Both aneurysms showed significant flow reduction after deployment of PED in computational simulation, corresponding to the flow diversion effect (Table 1). 


\section{Table 1}

Flow dynamics parameters of the fast occluding left and slow occluding right internal carotid artery aneurysm

\begin{tabular}{|c|c|c|c|c|c|c|}
\hline & \multicolumn{3}{|c|}{$\begin{array}{l}\text { Left aneurysm (fast } \\
\text { occlusion) }\end{array}$} & \multicolumn{3}{|c|}{$\begin{array}{l}\text { Right aneurysm (slow } \\
\text { occlusion) }\end{array}$} \\
\hline & $\begin{array}{l}\text { Before } \\
\text { PED }\end{array}$ & $\begin{array}{l}\text { After } \\
\text { PED }\end{array}$ & $\begin{array}{l}\text { Change } \\
(\%)\end{array}$ & $\begin{array}{l}\text { Before } \\
\text { PED }\end{array}$ & $\begin{array}{l}\text { After } \\
\text { PED }\end{array}$ & $\begin{array}{l}\text { Change } \\
(\%)\end{array}$ \\
\hline $\begin{array}{l}\text { Peak velocity } \\
(\mathrm{m} / \mathrm{s})\end{array}$ & 0.28 & 0.07 & -73.2 & 0.14 & 0.10 & -33.2 \\
\hline $\begin{array}{l}\text { Volume influx } \\
(\mathrm{ml} / \mathrm{s})\end{array}$ & 1.42 & 0.22 & -84.8 & 3.60 & 1.96 & -45.7 \\
\hline $\begin{array}{l}\text { Blood turnover } \\
\text { time }(\mathrm{s})\end{array}$ & 0.43 & 2.85 & +565.9 & 1.26 & 2.3 & +82.6 \\
\hline $\begin{array}{l}\text { Wall shear } \\
\text { stress }\left(\mathrm{N} / \mathrm{m}^{2}\right)\end{array}$ & 2.48 & 0.62 & -75.0 & 2.15 & 0.82 & -62.0 \\
\hline
\end{tabular}

The fast-occluding left aneurysm showed greater reduction in peak velocity (73.2 vs. $33.2 \%$ ) and volume influx into the aneurysm (84.8 vs. $45.7 \%$ ) after PED treatment than the slow-occluding right aneurysm. The absolute peak velocity and volume influx after PED in the left aneurysm were also lower (0.07 vs. $0.10 \mathrm{~m} / \mathrm{s}$ and 0.22 vs. $1.96 \mathrm{ml} / \mathrm{s})$ (Fig. 3$)$.

\section{Fig. 3}

Flow pattern and velocity profile before and after PED in both aneurysms 


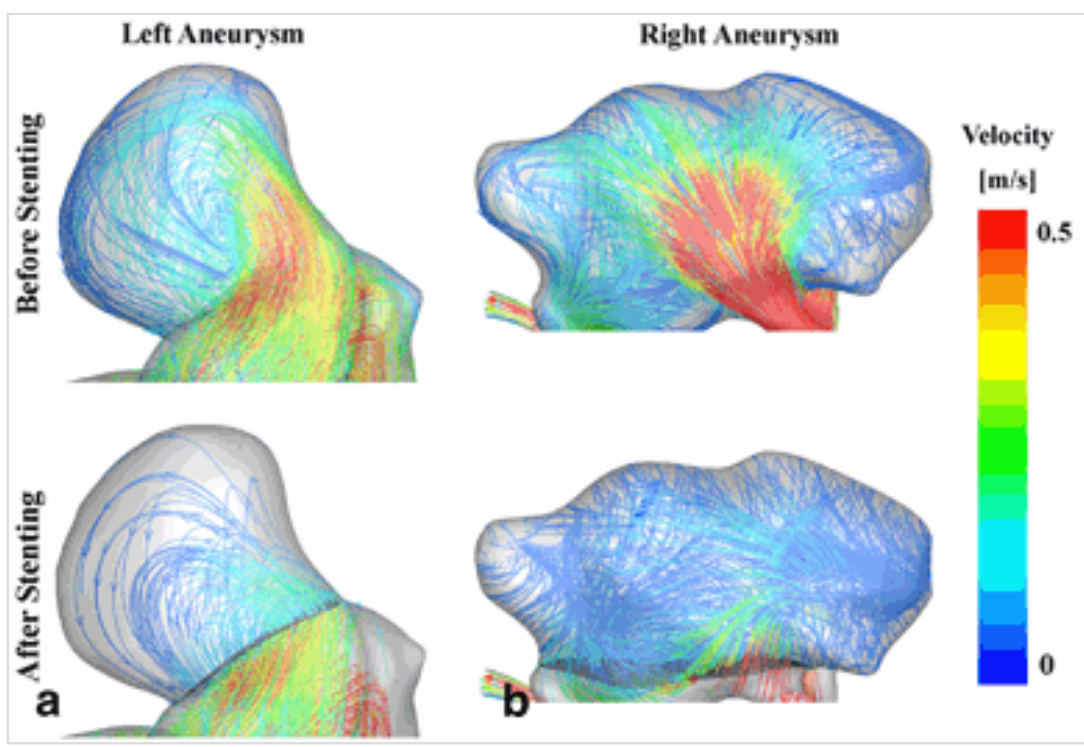

In the fast-occluding left aneurysm, an increase of turnover time by 565.9 $\%$ from 0.43 to $2.85 \mathrm{~s}$ after PED was observed. In contrast, the turnover time in the right aneurysm only increased by $82.6 \%$ from 1.26 to $2.30 \mathrm{~s}$ after flow diverter. The average wall shear stress over the aneurysm after stenting was reduced by $75.0 \%\left(2.48\right.$ to $\left.0.62 \mathrm{~N} / \mathrm{m}^{2}\right)$ in the left aneurysm, compared with $62.0 \%$ reduction in the right aneurysm $\left(2.15\right.$ to $\left.0.82 \mathrm{~N} / \mathrm{m}^{2}\right)$.

\section{Discussion}

The efficacy of flow diverters depends on the hemodynamic effect created to redirect blood flow away from the aneurysm sac, thereby creating stasis and gradual thrombosis within the aneurysm, leading to potential complete thrombosis and shrinkage of the aneurysm. Nevertheless, about one fifth of aneurysms were refractory to treatment [1].

Chung et al. performed CFD analysis on 36 rabbit aneurysms treated with PED and found that lower volume influx and lower intra-aneurysmal velocity were associated with faster occlusion [5]. On human subjects, two recent studies retrospectively compared aneurysms successfully treated by flow diverter with refractory ones and found that the volume influx after PED were significantly lower in successful cases [3, 6]. A recurrent limitation in these studies is that they failed to take into account the individual patient's blood properties such as anti-platelet reactivity and endothelial reaction after flow diverter, which may confound the clinical outcome. Directly correlating the hemodynamic parameters and clinical outcome in these cases may give misleading results.

The present study circumvented this limitation as both aneurysms were 
influenced by the hematological and vasculo-endothelial factors of the same patient. The coagulation function and the endothelial microenvironment in reaction to placement of stents in the two aneurysms should be comparable, thus the difference in occlusion time clinically would be largely due to the different hemodynamics in the two aneurysms, their geometry, and presence of PED.

The salient finding was the turnover time difference in the two aneurysms after PED treatment. The turnover time was defined by the ratio of the volume of the aneurysm to the flow rate and measures the time blood particles stay within the aneurysm sac [9]. In our patient, the fastoccluding aneurysm showed a remarkable increase of turnover time by more than fivefold, from 0.43 to $2.85 \mathrm{~s}$ after PED, whereas in the slowoccluding aneurysm it only increased by $82.6 \%$, from 1.26 to $2.30 \mathrm{~s}$. This parameter is particularly relevant in assessing flow diverter treatment because it corresponds to the degree of contrast stasis observed immediately after flow diverter deployment, which had been regarded by some interventionists as a reassuring sign of flow diversion effect. Our findings suggested that calculating the change in turnover time after PED deployment may be a plausible parameter to predict flow diversion effect. Analyzing the turnover time changes in a larger cohort is needed to confirm its predictive value.

The peak velocity and volume influx after PED in the fast-occluding aneurysm was reduced by 73.2 and $84.8 \%$ to $0.07 \mathrm{~m} / \mathrm{s}$ and $0.22 \mathrm{ml} / \mathrm{s}$, respectively. Conversely, the slow-occluding aneurysm showed significantly less reduction in peak velocity and volume influx (33.2 and $45.7 \%$ ) despite PED treatment. This is in agreement with previous flow dynamics studies $[5,6]$. Lower peak velocity and volume influx to the aneurysm were thus credible parameters, which can predict favorable flow diversion outcome.

\section{AQ1}

Our study was based on an ideally placed PED and used standard blood pressure and viscosity parameters, which may have limited the simulation accuracy. Future studies may aim to use patient-specific flow parameters as well as modeling the exact stent geometry after in vivo deployment for more precise evaluation. 


\section{Acknowledgments}

This study is funded by the Seed Funding Program for Basic Research of The University of Hong Kong and Innovation and Technology Fund (ITS/011/13) of the Government of the Hong Kong Special Administrative Region.

Compliance with Ethical Standards

Conflict of Interest On behalf of all the authors, the corresponding author states that there is no conflict of interest.

None to declare.

\section{References}

1. Brinjikji W, Murad MH, Lanzino G, Cloft HJ, Kallmes DF. Endovascular treatment of intracranial aneurysms with flow diverters: a meta-analysis. Stroke. 2013;44(2):442-7. doi:10.1161/strokeaha.112.678151.

2. Leung GK, Tsang AC, Lui WM. Pipeline embolization device for intracranial aneurysm: a systematic review. Clin Neuroradiol. 2012;22(4):295-303. doi:10.1007/s00062-012-0178-6.

3. Chong W, Zhang Y, Qian Y, Lai L, Parker G, Mitchell K. Computational hemodynamics analysis of intracranial aneurysms treated with flow diverters: correlation with clinical outcomes. AJNR Am J Neuroradiol. 2014;35(1):136-42. doi:10.3174/ajnr.A3790.

4. Kulcsar Z, Augsburger L, Reymond P, Pereira VM, Hirsch S, Mallik AS, et al. Flow diversion treatment: intra-aneurismal blood flow velocity and WSS reduction are parameters to predict aneurysm thrombosis. Acta Neurochir (Wien). 2012;154(10):1827-34. doi:10.1007/s00701-012-1482-2.

5. Chung B, Mut F, Kadirvel R, Lingineni R, Kallmes DF, Cebral JR. Hemodynamic analysis of fast and slow aneurysm occlusions by flow diversion in rabbits. J Neurointerv Surg. 2014;7(12):931-5. doi:10.1136/neurintsurg-2014-011412. 
6. Mut F, Raschi M, Scrivano E, Bleise C, Chudyk J, Ceratto R, et al. Association between hemodynamic conditions and occlusion times after flow diversion in cerebral aneurysms. J Neurointerv Surg. 2014;7(4):286-90. doi:10.1136/neurintsurg-2013-011080.

7. Tsang AC, Lai SS, Chung WC, Tang AY, Leung GK, Poon AK, et al. Blood flow in intracranial aneurysms treated with Pipeline embolization devices: computational simulation and verification with Doppler ultrasonography on phantom models. Ultrasonography. 2015;34(2):98-108. doi:10.14366/usg.14063.

8. Reymond P, Merenda F, Perren F, Rufenacht D, Stergiopulos N. Validation of a one-dimensional model of the systemic arterial tree. Am J Physiol Heart Circ Physiol. 2009;297(1):H208-22. doi:10.1152/ajpheart.00037.2009.

9. Kim M, Levy EI, Meng H, Hopkins LN. Quantification of hemodynamic changes induced by virtual placement of multiple stents across a wide-necked basilar trunk aneurysm. Neurosurgery. 2007;61(6):1305-12. doi:10.1227/01.neu.0000306110.55174.30. (discussion 12-3). 